\title{
ChemComm
}

\section{Localised corrosion in aluminium alloy 2024-T3 using in situ TEM $†$}

Cite this: Chem. Commun., 2013, 49, 10859

Received 1st September 2013, Accepted 2nd October 2013

DOI: $10.1039 / c 3 c c 46673 f$

www.rsc.org/chemcomm

An approach to carry out chemical reactions using aggressive gases in situ in a transmission electron microscope (TEM), at ambient pressures of $\mathbf{1 . 5}$ bar using a windowed environmental cell, called a nanoreactor, is presented here. The nanoreactor coupled with a specially developed holder with platinum tubing permits the usage of aggressive chemicals like hydrochloric acid $(\mathrm{HCl})$.

Environmental transmission electron microscopy (ETEM) is becoming an increasingly important field of study as the ability to create a controlled atmosphere around a specimen makes it possible to study several specimen-environment interactions on the nanoscale. ${ }^{1}$ In a TEM, which is usually operated under ultra-high vacuum, the controlled environment is achieved by one of the following approaches: ${ }^{2}$ the open type, using a differentially pumped vacuum system in which the reactive gases are spread around the specimen area of the TEM; and the closed type, using a windowed environmental cell. ${ }^{3}$ Over the years, the differentially pumped vacuum systems have proven to be very effective in achieving atomic resolution; however, the maximum achievable environmental pressures are in the order of 10-20 mbar. More recently, with the advancements in fabrication of microelectromechanical system (MEMS) based devices, environmental cells based on $\mathrm{Si}$ chips with thin membranes of silicon nitride $\left(\mathrm{Si}_{X} \mathrm{~N}_{Y}\right)$ have shown some intriguing possibilities for in situ experimentation. ${ }^{3-7}$

We have adopted the closed environmental cell based approach to facilitate the in situ ETEM studies. A functional MEMS device known as a nanoreactor has been developed in-house for this purpose. The nanoreactor consists of two facing chips fabricated using thin-film technology on a silicon substrate, as illustrated in Fig. 1(a). A photograph showing both sides of the top and bottom chips as well as a glued nanoreactor is presented in Fig. 1(b). As seen in Fig. 1(b), the central area of the chip is etched to create a $\sim 400 \mathrm{~nm}$ thin $\operatorname{Si}_{X} \mathrm{~N}_{Y}$

\footnotetext{
${ }^{a}$ Materials Innovation Institute, Mekelweg 2, 2628CD, Delft, The Netherlands

${ }^{b}$ Kavli Institute of Nanoscience, National Centre for HREM, Delft University of Technology, Lorentzweg 1, 2628 CJ, Delft, The Netherlands.

E-mail: S.R.K.Malladi@tudelft.nl

${ }^{c}$ FEI Company, Europe NanoPort, Achtseweg Noord 5, 5651 GG Eindhoven, The Netherlands

† Electronic supplementary information (ESI) available. See DOI: 10.1039/c3cc46673f
}

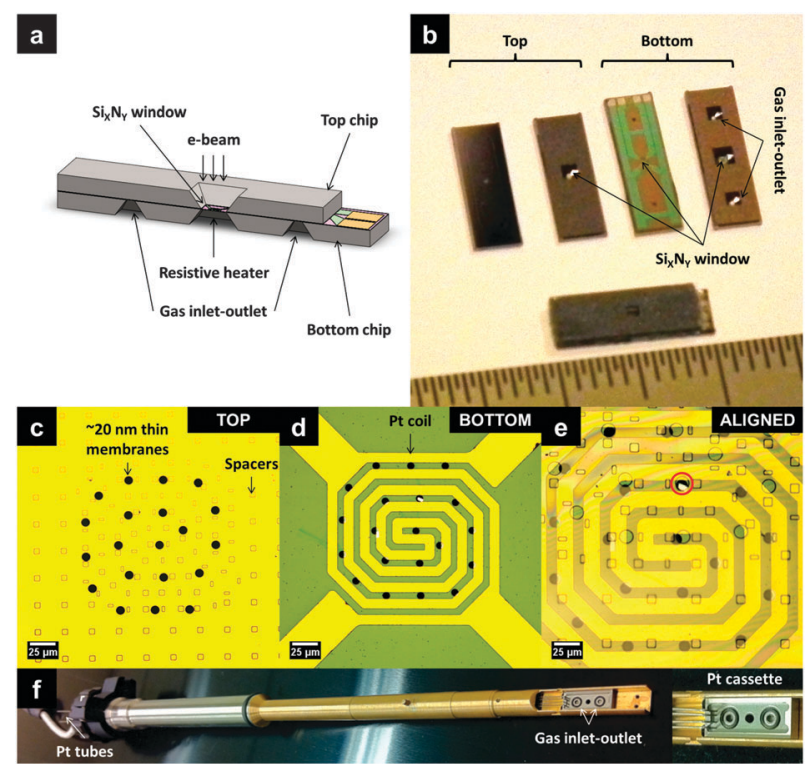

Fig. 1 (a) Conceptual sketch of a nanoreactor; (b) photographs of the top and the bottom chip, with an $\sim 400 \mathrm{~nm} \mathrm{Si} X \mathrm{~N}_{Y}$ window in $800 \times 800 \mu \mathrm{m}^{2}$ area; the inlet and the outlet for reactive gases in the bottom chip. Optical micrographs of the $400 \mathrm{~nm}$ $\mathrm{Si}_{X} \mathrm{~N}_{Y}$ window showing (c) top and (d) bottom chips, respectively, with $10 \mu \mathrm{m}$ circular holes over spanned with $\sim 20 \mathrm{~nm} \mathrm{Si} X \mathrm{~N}_{Y}$ membranes for electron transparency. The bottom chip is embedded with a Pt spiral for heating. The red encircled region in (e) shows aligned assembly. A glued nanoreactor is introduced into the TEM with the holder made, shown in (f). The holder has Pt tubing and the tip consists of a Pt cassette.

window which further consists of several $\sim 20 \mathrm{~nm}$ thin $\operatorname{Si}_{X} \mathrm{~N}_{Y}$ membranes for electron transparency, as shown by the dark circles in the subsequent optical micrographs in Fig. 1(c-e). The top chip has $\sim 200 \mathrm{~nm}$ spacers to prevent the stiction of the opposite membranes while the bottom chip consists of an embedded Pt wire to allow localised resistive heating to temperatures as high as $700{ }^{\circ} \mathrm{C}$. After aligning and assembling the chips together, Fig. 1(e), it is possible to study a number of gas-material interactions by varying temperatures as well as pressures. Using this system, we have demonstrated that it is possible to study catalysis in TEM as well as in scanning transmission X-ray microscopy (STXM) ${ }^{5}$ and (de)hydrogenation of hydrogen storage materials ${ }^{8}$ in situ. 
The main advantage of the window cell approach over the differentially pumped vacuum system is that by confining to a small region around the specimen it is possible to achieve much higher environmental pressures inside the microscope. It has been shown that it is possible to achieve atomic resolution ${ }^{3,6}$ close to atmospheric pressure $\left(0.18 \mathrm{~nm} \text { at } 500{ }^{\circ} \mathrm{C} \text { and } 1.2 \text { bar } \mathrm{H}_{2}\right)^{3}$ and even achieve pressures as high as 4.5 bar. $^{8}$ Furthermore, the added advantage of a windowed cell is the possibility to extend it to liquid systems. ${ }^{9}$ In the present study, we have shown the application of a nanoreactor to investigate localised corrosion in a well-studied aluminium alloy, AA 2024-T3, in a liquid-gas environment of oxygen bubbled through aqueous $\mathrm{HCl}$ of $\mathrm{pH}=3$ at $\sim 1.5$ bar pressure and at room temperature. Compared with our earlier studies, here we have used a holder equipped with a platinum cassette and platinum exchangeable gas tubing, Fig. 1(f), to allow reactive gas mixtures. Prior to the in situ corrosion experiments, to understand the alloy microstructure and to optimise the experimental parameters pertaining to specimen preparation and the reaction environment, we have carried out ex situ ${ }^{10}$ as well as quasi in situ ${ }^{11}$ corrosion experiments. A common feature observed in aluminium alloys is the presence of numerous intermetallic precipitates and dispersoids and segregated regions like precipitate free zones close to the grain boundaries, which exhibit distinctly different electrochemical characteristics compared to the surrounding microstructure. ${ }^{12}$ As a result, there are many localised nano-galvanic couples, which make these alloys susceptible to a spontaneous electrochemical attack. ${ }^{13}$ Due to the localization of a corrosive attack close to grain boundaries and precipitates, we have opted to carry out the in situ corrosion studies on specimens prepared by a Ga Focused Ion Beam (FIB) as it is possible to selectively prepare cross-sectional specimens in the vicinity of grain boundaries. The ability to produce specimens in the same thickness range, as well as the reliability to position the specimens accurately on the thin membranes of the nanoreactor, is another reason for choosing this method.

From the ex situ corrosion studies, depending on the morphology, location and compositional analysis from energy-dispersive X-ray (EDX) spectroscopy, the intermetallic precipitates have been classified into three categories: (1) large intermetallics with sizes typically in the range of $0.5-2 \mu \mathrm{m}$, enriched with $\mathrm{Fe}, \mathrm{Mn}$ and $\mathrm{Si}$ as well as intermetallics of the order of $0.5( \pm 0.1) \mu \mathrm{m}$, identified as the $\theta$-phase $\left(\mathrm{CuAl}_{2}\right)$ precipitates; (2) grain boundary precipitates enriched with $\mathrm{Cu}$ and $\mathrm{Mg}$, suggesting a mixture of the $\theta$-phase and the S-phase $\left(\mathrm{CuAl}_{2} \mathrm{Mg}\right)$; (3) plate type matrix precipitates with a width of $50( \pm 10) \mathrm{nm}$ and the length varying from 80 to $300 \mathrm{~nm}$, mostly enriched with $\mathrm{Cu}$ and $\mathrm{Mn}$, identified as $\mathrm{Al}_{20} \mathrm{Mn}_{3} \mathrm{Cu}_{2}$ type precipitates, commonly observed under these heat treatment conditions ${ }^{14}$ in this alloy. Fig. 2 shows a Scanning Transmission Electron MicroscopeAnnular Dark Field (STEM-ADF) image obtained for an AA 2024-T3 FIB specimen, revealing the plate type matrix precipitates.

Although these precipitates are largely present in the matrix, occasionally they can be found at the grain boundaries too. Depending on the alloying elements present, the precipitates can broadly be categorised into one of these two types: ${ }^{12-14}$ anodic, which are active compared to the matrix; and cathodic, which are more noble compared to the matrix. When the precipitates are cathodic, a circumferential attack is observed in the matrix. On the other hand, when the precipitate is anodic, selective dissolution of the

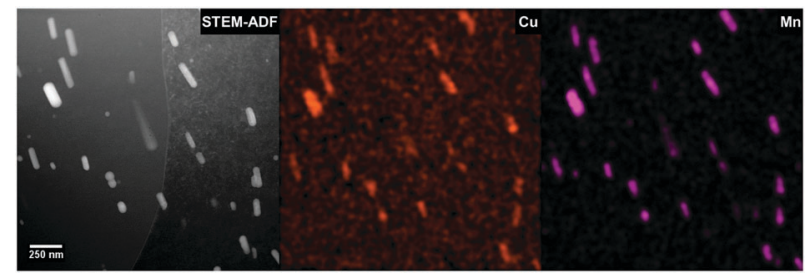

Fig. 2 STEM-ADF image and the corresponding EDX elemental maps of a FIB specimen of AA 2024-T3 reveal plate-like precipitates in the aluminium matrix enriched with $\mathrm{Cu}$ and $\mathrm{Mn}$. These plate type precipitates have been identified as the $\mathrm{Al}_{20} \mathrm{Mn}_{3} \mathrm{Cu}_{2}$ type, which exhibit cathodic behaviour with respect to the matrix.

intermetallic particle itself occurs, as observed from the quasi in situ corrosion studies. ${ }^{11}$ From the ex situ and quasi in situ corrosion studies, it has been decided to carry out in situ corrosion experiments at room temperature in an environment of oxygen bubbled through aqueous $\mathrm{HCl}$ of $\mathrm{pH}=3$ at $\sim 1.5$ bar pressure.

Fig. 3 shows the results from in situ corrosion studies just before and after exposing the AA 2024-T3 FIB specimen to the electrolyte of oxygen bubbled through aqueous $\mathrm{HCl}$ for a duration of approximately 5 hours. During the experiment, movies have been recorded using a CCD camera in bright-field (BF) mode. Fig. 3(a) shows the entire cross-section of a diagonally positioned FIB lamella before injecting the reactive gas mixture into the nanoreactor. The dark plate like features along the diagonal direction (indicated by green arrows), ranging from 70-400 $\mathrm{nm}$ in length and $30-100 \mathrm{~nm}$ in width are the intermetallic precipitates. The dark band (indicated by blue arrows) $\sim 300 \mathrm{~nm}$ in width at the bottom left corner of the image is an artefact, re-deposited material at the bottom of the trench during specimen preparation, which can in principle be minimised by lowvoltage ion milling for future studies. The ESI $\dagger$ movie shows the progression of the in situ study from the moment the reactive gas mixture is introduced into the nanoreactor. At the very beginning, several circular features (droplets of aqueous $\mathrm{HCl}$ ) are observed all over the specimen surface (images in the ESI $\dagger$ ). Up to $\sim 1$ hour, changes at edges of the specimen, corresponding to the blue and green arrows in Fig. 3(a) and migration of the $\mathrm{HCl}$ droplets, are observed. For the next 2 hours, some diffraction contrast change due to an orientation change of $\sim 0.1^{\circ}$ is observed close to the grain boundary precipitate (location 1); however no significant morphological changes were observed. After 3 hours, the $\mathrm{HCl}$ reservoir is refilled and the $\mathrm{HCl}$ droplets re-appear (images in ESI $\dagger$ ). It is from this point that significant microstructural changes are observed. From here on, the dark contrast of the grain boundary precipitate at location 1 appears to diminish. This change is evident at the end of 5 hours of exposure in Fig. 3(b), magnified images of location 1 in Fig. 3(c) and (d). This has been interpreted as de-alloying of the precipitate, indicating an anodic behaviour. The presence of anodic precipitates at grain boundaries in other specimens of the same alloy has been reported in our ex situ corrosion studies also. ${ }^{10}$ In the region surrounding plate-like precipitates in the matrix (identified as the $\mathrm{Al}_{20} \mathrm{Mn}_{3} \mathrm{Cu}_{2}$ type in other specimens of the same alloy), after nearly 4 hours of exposure, the growth of a region with a brighter contrast bound by a dark boundary is observed, Fig. 3(f). This is interpreted as a result of a surface corrosive attack of the aluminium matrix. Furthermore, significant etching of the aluminium matrix is observed all over the specimen surface. An important aspect to be considered 

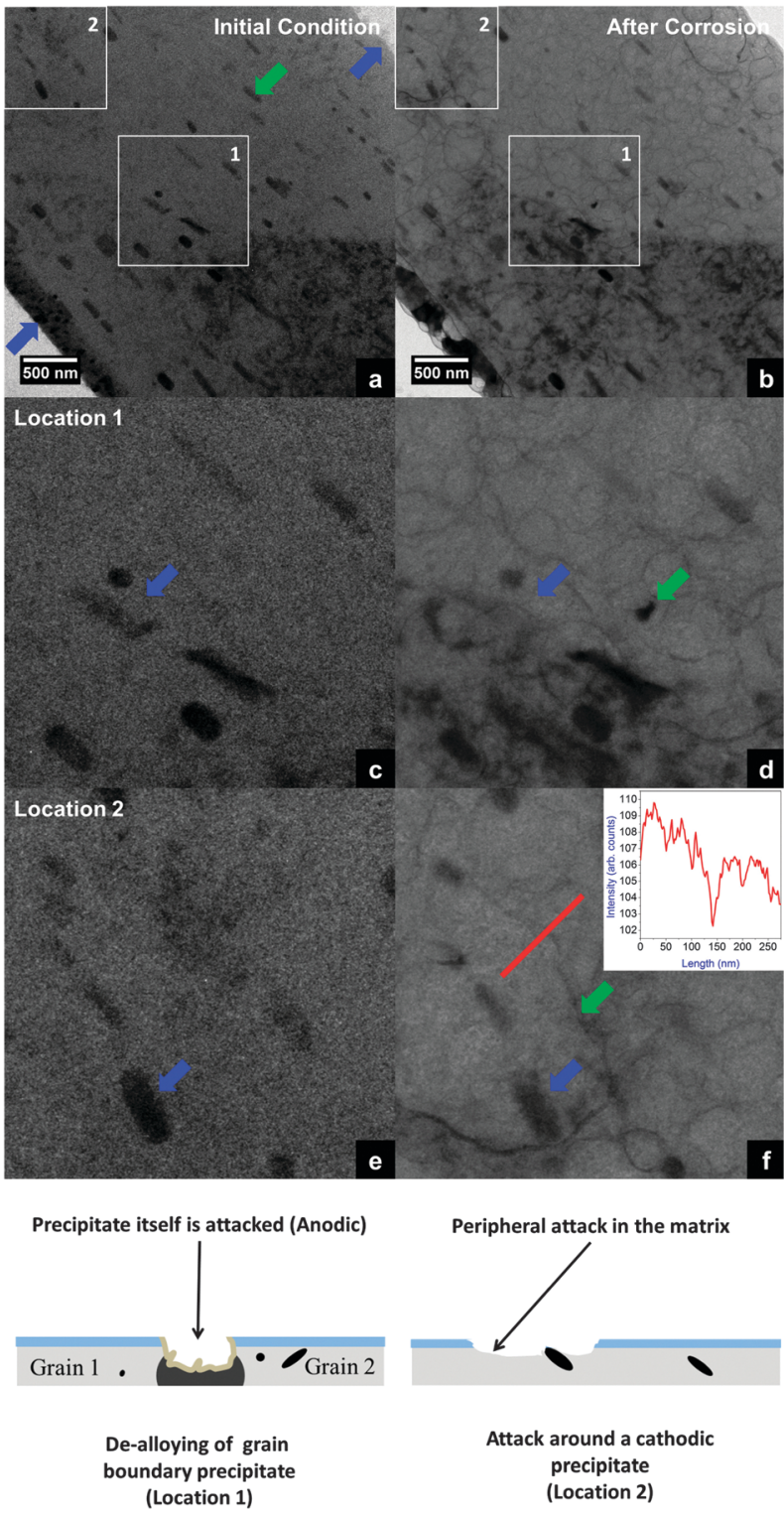

De-alloying of grain boundary precipitate (Location 1)
(Location 2)

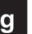

Nonetheless, the corrosion attack observed here is consistent with localised corrosion studies in aluminium alloys ${ }^{13,14}$ and based on these, conceptual sketches illustrating the corrosive attack around an anodic and a cathodic precipitate are presented in Fig. 3(g) and (h).

In this study, we have demonstrated an in situ approach to investigate corrosion reactions on a sub-micron scale. Although the exact $3 \mathrm{D}$ location of the precipitates across the cross-section is unclear from the BF-TEM images, as corrosion is a surface reaction, it is interpreted that the precipitates that have been attacked at locations 1 and 2 are closer to the surface. In future experiments this geometrical question can be answered by performing tomography before and after the in situ study. The silicon nitride membranes $(\sim 20 \mathrm{~nm}$ thick) of the nanoreactor withstand the pressures of $\sim 1.5$ bar throughout the experiment for 5 hours of constant electron beam illumination and flow of highly reactive gas mixtures (combination of $\mathrm{HCl}$, $\mathrm{H}_{2} \mathrm{O}$ and $\mathrm{O}_{2}$ ), without any noticeable reaction or damage. Despite this stability, it is better to speed up the corrosion process to make a more efficient use of the TEM, which can be obtained by carrying out corrosion tests at higher temperatures using the heater. Also, it is possible to combine the morphological changes during heat treatment with the corrosion behaviour of aluminium alloys. In short, this approach opens up possibilities to investigate morphological changes during chemical reactions in various gas-liquid-material systems on the nanoscale.

This research was carried out under the project number MC6.05222 as part of the Research Program of the Materials innovation institute M2i (www.m2i.nl), the former Netherlands Institute for Metals Research.

\section{Notes and references}

1 P. L. Gai, R. Sharma and F. M. Ross, MRS Bull., 2008, 33, 107-114.

2 E. P. Butler and K. F. Hale, in Practical Methods in Electron Microscopy, ed. M. Glauert, Elsevier Science Ltd, Amsterdam, 1981, pp. 239-308.

3 J. F. Creemer, S. Helveg, G. H. Hoveling, S. Ullmann, A. M. Molenbroek, P. M. Sarro and H. W. Zandbergen, Ultramicroscopy, 2008, 108, 993-998.

4 J. F. Creemer, S. Helveg, P. J. Kooyman, A. M. Molenbroek, H. W. Zandbergen and P. M. Sarro, J. Microelectromech. Syst., 2010, 19, 254-264.

Fig. 3 ( $a$ and b) BF-TEM images obtained for the AA 2024-T3 FIB specimen before and after in situ corrosion at room temperature and 1.5 bar pressure. The artefacts during specimen preparation are indicated by blue arrows. (c and d) At location 1 a grain-boundary precipitate (shown by blue arrows) is removed by de-alloying. Also the appearance of a dark feature (green arrow) close to the grain boundary precipitate is observed. (e and f) At location 2, the matrix surface around one of the precipitates (blue arrows) is attacked. An intensity profile along a $275 \mathrm{~nm}$ line (red) across the attacked region shows a higher intensity close to the precipitate as compared to that of the matrix beyond the dark contour (shown by a green arrow). ( $\mathrm{g}$ and $\mathrm{h}$ ) Schematics illustrating the corrosive attack.

here is the influence of the electron beam. The electron beam could induce a negative charge on the aluminium specimen surface, an effect similar to cathodic polarization, which can cause a resistance to corrosive attack, on the other hand, it could also dissociate $\mathrm{HCl}$ to its respective ions, resulting in making aluminium susceptible to corrosion by $\mathrm{Cl}^{-}$which is well documented. ${ }^{14}$ These two counterbalancing effects under the electron beam cannot be distinguished in this particular study but call for more experiments in this direction.

5 E. de Smit, I. Swart, J. F. Creemer, G. H. Hoveling, M. K. Gilles, T. Tyliszczak, P. J. Kooyman, H. W. Zandbergen, C. Morin, B. M. Weckhuysen and F. M. F. de Groot, Nature, 2008, 456, 222-225.

6 N. de Jonge, W. C. Bigelow and G. M. Veith, Nano Lett., 2010, 10, 1028-1031.

7 L. Allard, W. Bigelow, S. Overbury, D. Nackashi and J. Damiano, Microsc. Microanal., 2010, 16, 296-297.

8 T. Yokosawa, T. Alan, G. Pandraud, B. Dam and H. Zandbergen, Ultramicroscopy, 2012, 112, 47-52.

9 N. de Jonge, D. B. Peckys, G. J. Kremers and D. W. Piston, Proc. Natl. Acad. Sci. U. S. A., 2009, 106, 2159-2164.

10 S. R. K. Malladi, Q. Xu, F. D. Tichelaar, H. W. Zandbergen, F. Hannour, J. M. C. Mol and H. Terryn, Surf. Interface Anal., 2012, 45, 1619-1625.

11 S. R. K. Malladi, F. D. Tichelaar, Q. Xu, M. Y. Wu, H. Terryn, J. M. C. Mol, F. Hannour and H. W. Zandbergen, Corros. Sci., 2013, 69, 221-225.

12 A. Boag, A. E. Hughes, N. C. Wilson, A. Torpy, C. M. MacRae, A. M. Glenn and T. H. Muster, Corros. Sci., 2009, 51, 1565-1568.

13 A. Boag, A. E. Hughes, A. M. Glenn, T. H. Muster and D. McCulloch, Corros. Sci., 2011, 53, 17-26.

14 V. Guillaumin and G. Mankowski, Corros. Sci., 1999, 41, 421-438. 